\title{
Covid Patient Health Monitoring Using IoT During Quarantine
}

\author{
Lavanya Dhanesh ${ }^{\mathrm{a}, 1}$, Meena.T ${ }^{\mathrm{b}}$, Chrisntha.B ${ }^{\mathrm{b}}$, Gayathri.S ${ }^{\mathrm{b}}$, Devapriya.M.D ${ }^{\mathrm{b}}$ \\ ${ }^{a}$ Associate Professor, ${ }^{b} U G$ Student, Department of Electrical and Electronics \\ Engineering, Panimalar Institute of Technology, Chennai, TN, India
}

\begin{abstract}
The term "COVID" is breaking the hearts of the entire human community. The Corona virus is more infectious and is exceptionally irresistible, it is vital to isolate the patients and yet the specialists need to screen Corona virus patients as well. With the expanding increase in the number of Corona cases, the doctors find it difficult to keep track on the medical issue of isolated patients. To address this issue, we designed a distant IOT based screen framework, that considers observing of numerous Corona virus patients over the web. The system uses temperature sensor, respiratory sensor and pulse oximeter to measure the health parameters of the patients. If any oddity is detected in patient's health, the patient presses the emergency help button which we installed in our system. This will alert the doctor and the care taker over IOT remotely. Our system thus provides a safe health monitoring design, in order to prevent the disease spreading through Corona virus and monitoring the individual health of each patient.
\end{abstract}

Keywords. Corona patient, Quarantine, Zigbee, Arduino, RTC, IOT, Sensors.

\section{Introduction}

Corona virus has made the requirement for populace level screening, and telemedicine is obviously situated to empower this. As telemedicine has developed in the course of the most recent decade, distant checking arose as another and incredible methodology. Corona virus requires scaled co-operations with populaces in close to continuous. Distant checking has explicit operational and configuration includes that are appropriate for the COVID-19, particularly the offbeat correspondence. Checking can be utilized specifically to accumulate pandemic information and acquire continuous clinical input. As telemedicine proceeds to develop and advance, distant checking is arising as an important instrument for payers, suppliers, and general wellbeing authorities the same [1]. Thus this system helps in monitoring the quarantine people's health remotely with the help of IOT and wireless sensor network. Each patient will be enabled with the test kit with them. The system will continuously monitor the patient health parameters like heartbeat, temperature, and blood pressure values [2-3]. Once the value reaches any abnormal value the system will send an intimation to the doctor or care taker with the help of WSN network. Then the care taker can take immediate action. Corona virus is compelling a prompt re-examination and encounter with how to deal with such episodes. Innovation and our advanced society have on a very basic level empowered telemedicine, and now it is show time for such new modalities of "computerized wellbeing" to perform and succeed.

\footnotetext{
${ }^{1}$ Lavanya Dhanesh, Department of Electrical and Electronics Engineering, Panimalar Institute of Technology, Chennai, TN, India, Email: lavanyadhanesh2007@gmail.com.
} 


\section{Existing System}

\section{a. Problem 1}

In the existing system, health parameters of the patients cannot be monitoredremotely.

\section{b. Problem 2}

With the increase in number of patients, it is hard to screen them exclusively. And more specialists and medical attendants need to remain in the zone all the time to deal with the patients.

\section{c. Problem 3}

In the case that the patient under isolation leaves the zone, the information can't be passed.

\section{d. Problem 4}

This framework doesn't have any alert to the patient in isolation, as for any help, they cannot demand for it. This may prompt extreme issues.

\section{Proposed Method}

- Doctors get instant alert using an automatic health monitoring system.

- Reduces the time consumption of checking all the patients.

- Doctors can monitor the patients remotely without the risk of infection.

- In case if the patient under isolation leaves the conceded zone, the information will be passed to care taker and doctors using WSN.

- When the food is received in the right time a button is pressed by the patient for affirmation reason, where the time is known by RTC.

\section{Block Diagram}

Our Proposed system performs remote monitoring of patient health parameters using IOT and panic alert is sent to doctors as well as family members. To forestall the spreading of illness by giving programmed observing pack to every tolerant that will get the specialists far from the patient. In our Proposed system, Emergency help button is provided if any oddity detected which helps to send an alert through IOT remotely. The block diagram for the Patient section is depicted in Figure 1 and monitoring section is depicted in Figure 2.

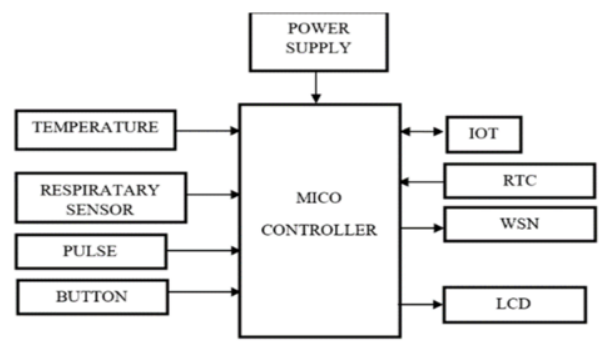

Figure 1. Patient Section

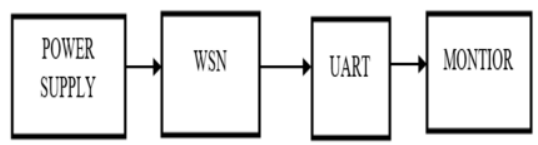

Figure 2. Monitoring Section 
The Zigbee is utilized in our proposed system, for controlling and checking the patient conditions from outside. Arduino Uno is a microcontroller board subject to the ATmega328P is used in our prototype model [3-5]. The program coding is written for various operations to be done in our proposed system using Embedded $\mathrm{C}$ and is being burned in the Arduino chip. We employ LM35 temperature sensors in our project which helps to yield voltage comparing with the standard reference temperature [6-8]. The Respiration Sensor is used in our proposed system, to screen stomach or thoracical breathing in biofeedback applications.

The Respiration Sensor can be worn over dress which may be of 1 or 2 layers of pieces of clothing between the sensor and the skin. The Respiration Sensor is ordinarily situated in the stomach area, with the central piece of the sensor. The sensor should be set tight enough to prevent inadequacy of pressing factor. Pulse Sensor is a masterminded fitting for Arduino which we employ in our system.

The sensor cuts onto a fingertip or ear tendon and connects directly into Arduino with some jumper joins [9-11]. On the front there is a round opening, which is the place where the LED exudes from the back. The LED focuses light into the fingertip, ear tendon or other fine tissue, and sensor examines the light that weaves back. The Real Time Clock (RTC)gives specific time and date which will be useful for monitoring the patient and for giving food, medicines at proper time without any delay and thereby informed the doctors and care taker[12-15].The circuit diagram of our proposed system with the sensors is shown in the Figure 3.

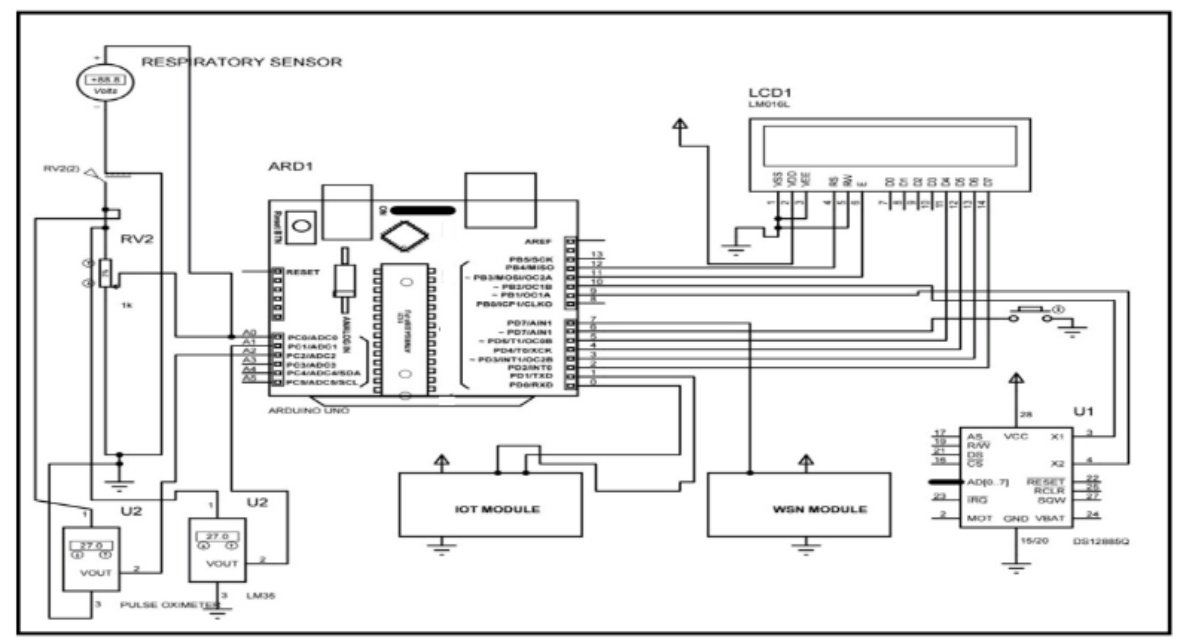

Figure 3. Circuit connections of the Proposed System

\section{Results and Discussions}

Our device monitors the breathing level, temperature and heart beat level of the COVID patientsand the controller checks for the abnormal value continuously.If any abnormally detected, alert is sent to the doctor or care taker with the help of WSN network for taking immediate action. The Prototype model of our proposed system is shown in the Figure 4 and the output programming results of the Patient conditions is shown in the Figure 5. 


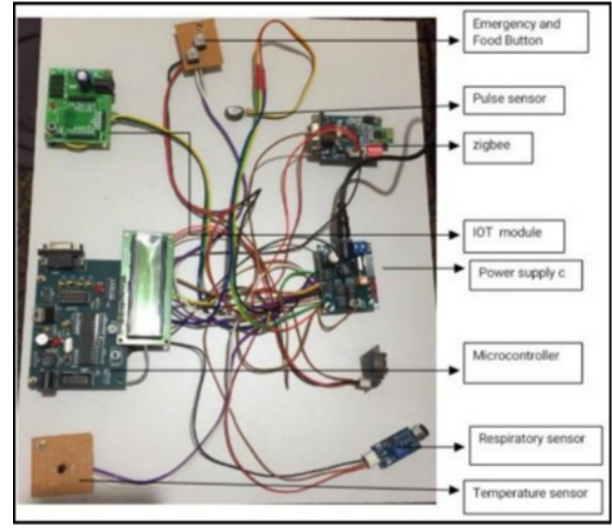

Figure 4. Prototype Model of Our Proposed System

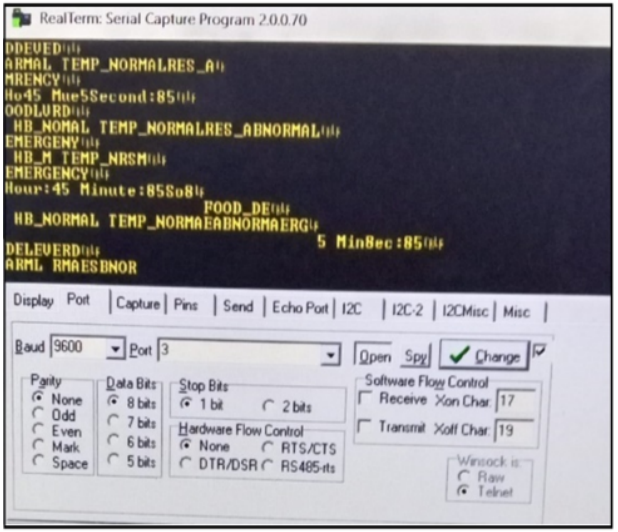

Figure 5. Output Programming Results

\section{Conclusion}

The current work was focused for vast major part around making life more worth for the people who affected by corona and subsequently kept in isolation. This new system has been made to diminish crafted by trained professionals and moreover the possibilities of ailment spreading. The structure has a twofold impact of both noticing and invigorating the checked data to the subject matter experts or to the regulators appropriated in the facilities in corona ward during the time of the pandemic situation.

\section{References}

[1] S. Marathe, D. Zeeshan, T. Thomas, and S. Vidhya, "A Wireless Patient Monitoring System using Integrated ECG module, Pulse Oximeter, Blood Pressure and Temperature Sensor,” Proc. - Int. Conf. Vis. Towar. Emerg. Trends Commun. Networking, ViTECoN 2019, pp. 1-4, 2019, doi: 10.1109/ViTECoN.2019.8899541.

[2] S. Nubenthan and K. Ravichelvan, "A wireless continuous patient monitoring system for dengue; WiMon,” Proc. 2017 Int. Conf. Wirel. Commun. Signal Process. Networking, WiSPNET 2017, vol. 2018Janua, pp. 2201-2205, 2018, doi:10.1109/WiSPNET.2017.8300150.

[3] P. W. Digarse and S. L. Patil, "Arduino UNO and GSM based wireless health monitoring system for patients,” Proc. 2017 Int. Conf. Intell. Comput. Control Syst. ICICCS 2017, vol. 2018-Janua, pp. 583588, 2017, doi: 10.1109/ICCONS.2017.8250529.

[4] Dr.Lavanya Dhanesh, "Automated Intimation to Ambulance for Emergency Medical Service and Traffic Clearance Using Internet of Things (IOT), in the International Journal for Research in Applied Science \& Engineering Technology (IJRASET), ISSN: 2321-9653, Volume: 6, Issue: 3, Mar-2018.

[5] Dr.Lavanya Dhanesh, "An Smart Load Management System For Homes Using IOT", in the International Journal of Advance Research in Engineering, Science \& Technology, e-ISSN: 2393-9877, Volume: 5, Issue: 3, Mar-2018.

[6] Lavanya Dhanesh, Dr.P.Murugesan, "Smart Scheduling of the Real-Time Tasks Using the Cyclic Priority Preemptive Pipeline Scheduling Algorithm" in the International Journal named "Journal of Computational and Theoretical Nano Science" ISSN 1546-1955 Volume 14,Number 3, pp.1-8.

[7] Dr.Lavanya Dhanesh, Dr.S.Deepa , “ Enhanced and Energy-Efficient Program Scheduling for Heterogeneous Multi-Core Processors System”, Lecture notes in Electrical Engineering ,2020) 665, pp 737-747..

[8] Lavanya Dhanesh, Dr.P.Murugesan (2018), “A Novel Approach in Scheduling Of the Real- Time Tasks In Heterogeneous Multicore Processor with Fuzzy Logic" in the International Journal named 
"International Journal of Power Electronics and Drive System (IJPEDS)" ISSN: 2088-8694, Vol. 9, No. 1 , pp. 80-88.

[9] Dr.Lavanya Dhanesh, "Implementation of IOT Based Self Learning Home Energy Management System", in the International Journal of Advanced Research in Electrical, Electronics and Instrumentation Engineering, ISSN 2278-8875, Vol. 8, Issue 3, March 2019.

[10] Lavanya Dhanesh, Dr.P.Murugesan (2015), "Power Saving of The CPU By Improving The Performance of The Real - Time System Kernal Using The PSCPPTS Algorithm" in the International Journal named "International Journal of Applied Engineering Research"ISSN 0973-4562 Volume 10, Number 5 (2015) pp. 12465-12473.

[11] Lavanya Dhanesh, Dr.P.Murugesan (2015), "Analysing the WCET by implementing Cyclic Priority Pre- Emptive Task Scheduling algorithm" in the International Journal named "Far East Journal Of Mathematical Sciences" ISSN 0972-0871 Volume 97,Number 6, 2015 pp. 667-688.

[12] G. J. Bharat Kumar, "Internet of Things (IoT) and Cloud Computing based Persistent Vegetative State Patient Monitoring System: A remote Assessment andManagement,” Proc. Int. Conf. Comput. Tech. Electron. Mech. Syst. CTEMS 2018, pp. 301-305, 2018, doi:10.1109/CTEMS.2018.8769175.

[13] T. K. Ramesh and C. V. Giriraja, "Wirelesss Sensor network protocol for patient monitoring system," 2017 Int. Conf. Comput. Commun. Informatics, ICCCI 2017, pp. 5-8, 2017, doi: 10.1109/ICCCI.2017.8117798.

[14] S. Shaikh, D. Waghole, P. Kumbhar, V. Kotkar, and P. Awaghade, "Patient monitoring system using IoT,” 2017 Int. Conf. Big Data, IoT Data Sci. BID 2017, vol. 2018- January, pp. 177-181, 2018, doi:10.1109/BID.2017.8336594.

[15] Vengatesan, D. K., Naik, D. R., Ramkumar, M., \& Bhaskar, T. Review On Cost Optimization And Dynamic Replication Methodologies In Cloud Data Centers. Journal of Advanced Research in Dynamical and Control Systems, 9.

[16] S. P. McGrath, I. M. Perreard, M. D. Garland,K. A. Converse, and T. A. Mackenzie,"Improving Patient Safety and Clinician Workflow in the General Care Setting With Enhanced Surveillance Monitoring," IEEE J. Biomed. Heal. Informatics, vol. 23, no. 2, pp. 857-866, 2019, doi: 10.1109/ JBHI.2018.2834863. 